\title{
A new integrated MCDM approach for lecturers' research productivity evaluation
}

\author{
Nguyen Anh Tuan ${ }^{a, b}$, Truong Thi Hue ${ }^{a^{*}}$, Luong Thuy Lien ${ }^{c}$, Truong Duc Thaod, Nguyen Duy \\ Quyet $^{\mathrm{b}}$, Luu Huu Van and Luong Tram Anh ${ }^{\mathrm{a}}$
}

${ }^{a}$ VNU University of Economics and Business, Vietnam National University, Hanoi, 144 Xuan Thuy Road, Hanoi 100000, Vietnam

${ }^{b}$ Hanoi University Physical Education and Sprots, Phung Chau, Chuong My, Hanoi 100000, Vietnam

${ }^{c} V N U$ University of Social Sciences and Humanities, Vietnam National University, Hanoi, 336 Nguyen Trai road, Thanh Xuan, Hanoi 100000, Vietnam

${ }^{d}$ Management Faculty, Thang Long University, Nghiem Xuan Yem, Hanoi 100000, Vietnam

\begin{tabular}{l}
\hline C H R O N I C L E \\
\hline Article history: \\
Received February 23, 2020 \\
Received in revised format: \\
March 29, 2020 \\
Accepted April 232020 \\
Available online \\
April 23, 2020 \\
\hline Keywords: \\
TOPSIS \\
AHP \\
Interval neutrosophic sets \\
Fuzzy sets \\
MCDM \\
Lecturers' research productivity \\
evaluation \\
\hline
\end{tabular}

\begin{abstract}
A B S T R A C T
Evaluating research productivity of lecturer is a vital process of universities for teaching improvement and administrative decision making. Lecturers' research productivity evaluation is a difficult and sensitive problem which has many objective and subjective criteria, complexity and imprecision. Therefore, the evaluation of lecturers' research productivity can be viewed as a multi-criteria decision making (MCDM) problem in vague environment. This study develops an integrated MCDM approach for evaluating the lecturers' research productivity. In the proposed approach, a fuzzy analytic hierarchy process (AHP) is applied to determine the weights of criteria. A Technique for Order Preference by Similarity to Ideal Solution (TOPSIS) method using interval neutrosophic sets is further adopted for showing the preference order of the lecturers' research productivity in an educational organization. Finally, the proposed approach is applied to solve the lecturers' research productivity evaluation problem in the case of University of Economics and Business, Vietnam National University, Hanoi (UEB-VNU).
\end{abstract}

(C) 2020 by the authors; licensee Growing Science, Canada.

\section{Introduction}

Evaluating lecturers' research productivity plays an important role in determining the quality of training and the position of universities (McKee \& Tew, 2013). In the process of evaluating lecturers' research productivity, many objectives and subjective criteria must be considered such as number and quality of scientific publications, number of books, number of postgraduate students completed under supervision as main supervisor, research grants secured as project leader, the average number of citations per publication, etc. (Costa and Oliveira, 2012; Dat et al., 2019; Tauhed et al., 2019; Do et al., 2020). Therefore, the evaluation of lecturers' research productivity can be viewed as a complex multi-criteria decision making (MCDM) problem in vague environment (Ateş et al., 2006). Many studies have indicated the criteria and proposed fuzzy MCDM approaches for evaluating the lecturers' performance in literature. Wong and Tierney (2001) pointed out that the research results of scientists are often evaluated by publications, presentations, and sometimes also by donations. Kaya and Weber (2003) argued that the research productivity of lecturers is measured by the opportunities for the development and professional affirmation of lecturers, such as seminar reports and scientific conference reports and the number of submitted proposals for sponsorship or received research grants. Similarly, according to 
Hedjazi and Behravan (2011), research results are related to creative ideas that, after being studied, are published into projects in journals, newspapers, or pattern registers or academic materials. In general, researchers argued that publications are often used as a means of assessing the research capacity of researchers around the world. Cummings and Shin (2014) argued that the research capacity, especially published publications, now becomes the criterion for recruitment, promotion and retention of positions and titles in all research universities around the globe in order to ensure that this is a resource for the implementation of important research goals of universities. This is also the most important criteria for ranking universities in the world in reputed ranking systems such as THE, SJTU, QS. Chang and Wang (2016) proposed a cloud MCDM model for teacher evaluation in higher education which is involving subjectivity, imprecision and fuzziness. Four major aspects were used to evaluate teacher including code of ethics, teaching standards, academic standards and practical results. Tauhed et al. (2019) defined the research performance as an outcomes of research activities that are visible and passed on to others in a form of products which are most commonly seen as publications of journal article, book and research funding.

Costa and Oliveira (2012) applied a multicriteria decision analysis model to evaluate faculty. Four main criteria and sub-criteria were used in their study including teaching (pedagogical publications, student supervision, course teaching), research (scientific publications, scientific projects), knowledge transfer (patents, legislation, norms and technical publications; service, consultancy and dissemination of science and technology), and university management. Jaramillo et al. (2017) obtained a model based on MCDM for the teacher ranking of an Ecuadorian University supported by the concept of multiple criteria such as administrative management, research, teaching and community engagement. Karmaker et al. (2018) applied a hybrid MCDM model to evaluate teachers' performance of a renowned engineering university of Bangladesh. Specifically, the analytic hierarchy process (AHP) was utilized to determine the weights of attributes (key performance indicators) and the Technique for Order Preference by Similarity to Ideal Solution (TOPSIS) was adopted for showing the preference order of the teachers in an educational organization. In their study, fifteen sub-criteria of five main performance evaluation indicators were considered to validate the proposed model including subject knowledge (ability of teaching, understand student psychology, problem solving capability), ability of commutation (clear idea, accessibility, power of explanation), discipline (fair, attitude, well organized), co-operative (good guidance, dedicated, power of motivation), creative (positive reinforcement, passionate, inspirational). Recently, a single valued neutrosophic set (SVNS) proposed by Wang et al. (2005a), which is a generalization of fuzzy set, has been magnificently applied in different fields, including decision-making problems. Wang et al. (2005) further proposed an interval neutrosophic set (INS) and presented the set-theoretic operators of INS. The theoretical and practical works in INSs have rapidly progressed. However, a limited study has proposed the MCDM approaches using SVNS and/or INS for evaluating lecturers' research productivity. Dat et al. (2019) developed a TOPSIS approach based on interval linguistic interval complex neutrosophic set to select lecturer in the case study of University of Economics and Business - Vietnam National University (UEB-VNU). Six selection criteria were applied in their study including number of publications, quality of publications, personality factors, activity in professional society, classroom teaching experience, and fluency in a foreign language. Duc et al. (2020) developed a novel TOPSIS method using interval-valued complex neutrosophic set to evaluate the lecturers' performance. Many sub-criteria were used in their model such as the scientific publication activities, supervising postgraduate students, lecturing activities, evaluation of Student and cooperation in research projects, vv. To our knowledge, no prior studies have developed an integrated fuzzy AHP and INS-TOPSIS for lecturers' research productivity evaluation.

This paper aims to propose an integrated fuzzy AHP and INS-TOPSIS for evaluating lecturers' research productivity. In the proposed approach, a fuzzy analytic hierarchy process is applied to determine the weights of criteria. Further, the INS-TOPSIS is adopted to evaluate and rank the lecturers' research productivity. Finally, the proposed approach is applied to solve lecturers' research productivity 
evaluation in the case of UEB-VNU. The organization of this paper is as follows. Section 2 introduces the concepts of fuzzy sets, neutrosophic sets, SVNS, INS and their operations. Section 3 proposes the integrated fuzzy AHP and INS-TOPSIS. A numerical example with real dataset is implemented to show the procedure and advantage of the proposed method in Section 4. Finally, conclusion is given in Section 5.

\section{Preliminaries}

Definition 1. A real fuzzy number $A$ is described as any fuzzy subset of the real line $R$ with membership function $A(x)$ that can be generally be defined as (Dubois \& Prade, 1978):

(a) $f_{A}$ is a continuous mapping from $R$ to the closed interval $[0, \omega]$.

(b) $f_{A}(x)=0$, for all $x \in(-\infty, a]$;

(c) $f_{A}$ is strictly increasing on $[a, b]$;

(d) $f_{A}(x)=\omega$, for all $x \in[b, c]$;

(e) $\quad f_{A}$ is strictly decreasing on $[c, d]$;

(f) $\quad f_{A}(x)=0$, for all $x \in(d, \infty]$,

where $a, b, c$ and $d$ are real numbers. Unless elsewhere specified, this research assumed that $A$ is convex and bounded (i.e. $-\infty<a, d<\infty$ ).

Definition 2. The fuzzy number $A=(a, b, c, d ; \varpi)$ is a trapezoidal fuzzy number if its membership function is given by (Dubois and Prade, 1978):

$$
f_{A}(x)=\left\{\begin{array}{lc}
f_{A}^{L}(x), & a \leq x \leq b, \\
\varpi, & b \leq x \leq c, \\
f_{A}^{R}(x), & c \leq x \leq d, \\
0, & \text { otherwise }
\end{array}\right.
$$

where $f_{L}^{A}(x)$ and $f_{A}^{R}(x)$ are the left and right membership functions of $A$, respectively. If $\varpi=1$, then $A$ is a normal fuzzy number; otherwise, it is said to be a non-normal fuzzy number. If $b \neq c, A$ is referred to as a fuzzy interval or a flat fuzzy number. If $f_{A}^{L}(x)$ and $f_{A}^{R}(x)$ are both linear, then $A$ is referred to as a trapezoidal fuzzy number and is usually denoted by $A=(a, b, c, d ; \varpi)$ or simply $A=(a, b, c, d)$ if $\varpi=1$. In particular, when $b=c$, the trapezoidal fuzzy number is reduced to a triangular fuzzy number, and can be denoted by $A=(a, b, d ; \varpi)$ or $A=(a, b, d)$ if $\varpi=1$.

Definition 3. Neutrosophic Set, single-valued neutrosophic set and interval-valued neutrosophic set Let $\mathrm{U}$ be a universe of discourse and a set $\mathrm{B} \subset \mathrm{U}$, such that

$$
B=\left\{x,\left(T_{B}(x), I_{B}(x), F_{B}(x)\right), x \in U\right\},
$$

where $\mathrm{B}$ is characterized by a truth membership function $T_{B}$, an indeterminacy membership function $I_{B}$, and a falsehood membership function $F_{B} . \mathrm{T}_{\mathrm{B}}(\mathrm{x}), \mathrm{I}_{\mathrm{B}}(\mathrm{x}), \mathrm{F}_{\mathrm{B}}(\mathrm{x}) \subseteq[0,1]$ are real subsets, for all $\mathrm{x} \in$ $\mathrm{U}$, is called a neutrosophic set $(\mathrm{NS})$ (Smarandache, 1998). If $\mathrm{T}_{\mathrm{B}}(\mathrm{x}), \mathrm{I}_{\mathrm{B}}(\mathrm{x}), \mathrm{F}_{\mathrm{B}}(\mathrm{x}) \in[0,1]$ are real (crisp) numbers, for all $\mathrm{x} \in \mathrm{U}$, then $\mathrm{B}$ is called a single-valued neutrosophic set (SVNS) (Wang et al., 2005a). If $\mathrm{T}_{\mathrm{A}}(\mathrm{x}), \mathrm{I}_{\mathrm{A}}(\mathrm{x}), \mathrm{F}_{\mathrm{A}}(\mathrm{x}) \subseteq[0,1]$ are real intervals, for all $\mathrm{x} \in \mathrm{U}$, then $\mathrm{N}$ is called an interval-valued neutrosophic set (Wang et al., 2005b).

Definition 4. Operational Rules of the Interval Neutrosophic Values

Let $A_{1}=\left(\left[T_{1}^{L}, T_{1}^{U}\right],\left[I_{1}^{L}, I_{1}^{U}\right],\left[F_{1}^{L}, F_{1}^{U}\right]\right) \quad$ and $A_{2}=\left(\left[T_{2}^{L}, T_{2}^{U}\right],\left[I_{2}^{L}, I_{2}^{U}\right],\left[F_{2}^{L}, F_{2}^{U}\right]\right) \quad$ be two interval neutrosophic values. The operational rules of interval neutrosphic values are then defined as follows: 
The complement of $A_{1}$ is

$$
\begin{aligned}
& \bar{x}=\left(\left[F_{1}^{L}, F_{1}^{U}\right],\left[1-I_{1}^{U}, 1-I_{1}^{L}\right],\left[T_{1}^{L}, T_{1}^{U}\right]\right) \\
& A_{1} \oplus A_{2}=\left(\left[T_{1}^{L}+T_{2}^{L}-T_{1}^{L} T_{2}^{L}, T_{1}^{U}+T_{2}^{U}-T_{1}^{U} T_{2}^{U}\right],\left[I_{1}^{L} I_{2}^{L}, I_{1}^{U} I_{2}^{U}\right],\left[F_{1}^{L} F_{2}^{L}, F_{1}^{U} F_{2}^{U}\right]\right. \\
& A_{2} \otimes A_{2}=\left(T_{1}^{L} T_{2}^{L}, T_{1}^{U} T_{2}^{U}\right],\left[I_{1}^{L}+I_{2}^{L}-I_{1}^{L} I_{2}^{L}, I_{1}^{U}+I_{2}^{U}-I_{1}^{U} I_{2}^{U}\right], \\
&\left.\quad\left[F_{1}^{L}+F_{2}^{L}-F_{1}^{L} F_{2}^{L}, F_{1}^{U}+F_{2}^{U}-F_{1}^{U} F_{2}^{U}\right]\right) \\
& n A_{1}=\left(\left[1-\left(1-T_{1}^{L}\right)^{n}, 1-\left(1-T_{1}^{U}\right)^{n}\right],\left[\left(I_{1}^{L}\right)^{n},\left(I_{1}^{U}\right)^{n}\right],\left[\left(F_{1}^{L}\right)^{n},\left(F_{1}^{U}\right)^{n}\right]\right), n>0 \\
& A_{1}^{n}=\left(\left[\left(T_{1}^{L}\right)^{n},\left(T_{1}^{U}\right)^{n}\right],\left[1-\left(1-I_{1}^{L}\right)^{n}, 1-\left(1-I_{1}^{U}\right)^{n}\right],\left[1-\left(1-F_{1}^{L}\right)^{n}, 1-\left(1-F_{1}^{U}\right)^{n}\right]\right), n>0
\end{aligned}
$$

\section{Definition 5. Distance between two Neutrosophic Values}

Let $x=\left(\left[T_{1}^{L}, T_{1}^{U}\right],\left[I_{1}^{L}, I_{1}^{U}\right],\left[F_{1}^{L}, F_{1}^{U}\right]\right)$, and $y=\left(\left[T_{2}^{L}, T_{2}^{U}\right],\left[I_{2}^{L}, I_{2}^{U}\right],\left[F_{2}^{L}, F_{2}^{U}\right]\right)$ be two INVs. The Hamming and Euclidian distances between $x$ and $y$ are defined respectively as follows:

$$
\begin{aligned}
& d_{H}(x, y)=\frac{1}{6}\left(\left|T_{1}^{L}-T_{2}^{L}\right|+\left|T_{1}^{U}-T_{2}^{U}\right|+\left|I_{1}^{L}-I_{2}^{L}\right|+\left|I_{1}^{U}-I_{2}^{U}\right|+\left|F_{1}^{L}-F_{2}^{L}\right|+\left|F_{1}^{U}-F_{2}^{U}\right|\right) \\
& d_{E}(x, y)=\sqrt{\frac{1}{6}\left(\begin{array}{l}
\left(T_{1}^{L}-T_{2}^{L}\right)^{2}+\left(T_{1}^{U}-T_{2}^{U}\right)^{2}+\left(I_{1}^{L}-I_{2}^{L}\right)^{2} \\
+\left(I_{1}^{U}-I_{2}^{U}\right)^{2}+\left(F_{1}^{L}-F_{2}^{L}\right)^{2}+\left(F_{1}^{U}-F_{2}^{U}\right)^{2}
\end{array}\right)}
\end{aligned}
$$

\section{Proposed new integrated MCDM approach for Lecturers' research productivity evaluation}

This section develops a new integrated MCDM approach for lecturers' research productivity evaluation. The steps of the proposed integrated MCDM approach are as follows:

\subsection{Aggregating the ratings of lecturers' research productivity versus criteria}

Let $x_{\text {efg }}=\left(\left[T_{\text {efg }}^{L}, T_{\text {efg }}^{U}\right],\left[I_{\text {efg }}^{L}, I_{\text {efg }}^{U}\right],\left[F_{\text {efg }}^{L}, F_{\text {efg }}^{U}\right]\right), \quad e=1, \ldots, s, f=1, \ldots, t, g=1, \ldots, h$ be the suitability rating assigned to lecturers $A_{e}$, by decision-makers $D_{g}$, for " $H O W s$ " criteria $C_{f}$. The averaged suitability rating, $x_{e f}=\left(\left[T_{e f}^{L}, T_{e f}^{U}\right],\left[I_{e f}^{L}, I_{e f}^{U}\right],\left[F_{e f}^{L}, F_{e f}^{U}\right]\right)$, can be evaluated as:

$$
x_{e f}=\frac{1}{h} \otimes\left(x_{e f 1} \oplus x_{e f 2} \oplus \ldots \oplus x_{e f g} \oplus \ldots \oplus x_{e f h}\right),
$$

where:

$$
\begin{gathered}
T_{e f}^{L}=1-\left(1-\sum_{q=1}^{h} T_{e f g}^{L}\right)^{1 / h} ; T_{e f}^{U}=1-\left(1-\sum_{q=1}^{h} T_{e f g}^{U}\right)^{1 / h} I_{e f}^{L}=\left(\sum_{q=1}^{h} I_{e f g}^{L}\right)^{1 / h} ; I_{e f}^{U}=\left(\sum_{q=1}^{h} I_{e f g}^{U}\right)^{1 / h} \\
F_{e f}^{L}=\left(\sum_{q=1}^{h} F_{e f g}^{L}\right)^{1 / h} ; F_{e f}^{U}=\left(\sum_{q=1}^{h} F_{e f g}^{U}\right)^{1 / h} .
\end{gathered}
$$

\subsection{Aggregating the importance weights of lecturers' research productivity evaluation criteria}

This study applies the fuzzy AHP proposed by Chang (1996) to determine the weights of lecturers' research productivity criteria. The Chang's fuzzy AHP approach is briefly presented as follows:

Let $X=\left\{x_{1}, x_{2}, \ldots, x_{n}\right\}$ be an object set, and $U=\left\{u_{1}, u_{2}, \ldots, u_{m}\right\}$ be a goal set. According to Chang's extent analysis, each object is taken and an extent analysis for each goal $\left(g_{i}\right)$ is performed respectively. 
Therefore, $m$ extent analysis values for each object can be obtained as $M_{g_{i}}^{1}, M_{g_{i}}^{2}, \ldots, M_{g_{i}}^{n}, i=1,2, \ldots, n$, where $M_{g_{i}}^{j}(j=1,2, \ldots, m)$ are triangular fuzzy numbers (TFNs). Assume that $M_{g_{i}}^{j}$ be values of extent analysis of $i$ th object for $m$ goals. The value of fuzzy synthetic extent, $S_{i}$ is defined as:

$$
S_{i}=\sum_{j=1}^{m} M_{g_{i}}^{j} \otimes\left[\sum_{i=1}^{n} \sum_{j=1}^{m} M_{g_{i}}^{j}\right]^{-1}
$$

where, $\sum_{j=1}^{m} M_{g_{i}}^{j}=\left(\sum_{j=1}^{m} l_{i j}, \sum_{j=1}^{m} m_{i j}, \sum_{j=1}^{m} u_{i j},\right), j=1,2, \ldots m, i=1,2, \ldots n$.

Let $M_{1}=\left(l_{1}, m_{1}, u_{1}\right)$ and $M_{2}=\left(l_{2}, m_{2}, u_{2}\right)$ be two TFNs, the degree of possibility of $M_{1} \geq M_{2}$ is defined as follows:

$$
V\left(M_{1} \geq M_{2}\right)=\sup _{x \geq y}\left[\min \left(\mu_{M_{1}}(x), \mu_{M_{2}}(x)\right)\right]
$$

The membership degree of possibility can be expressed as in Eq. (12)

$$
V\left(M_{1} \geq M_{2}\right)=\operatorname{hgt}\left(M_{1} \cap M_{2}\right)=\mu_{M_{2}}(d)= \begin{cases}1 & \text { if } m_{1} \geq m_{2} \\ 0 & \text { if } l_{1} \geq u_{2} \\ \frac{l_{1}-u_{2}}{\left(m_{2}-u_{2}\right)-\left(m_{1}-l_{1}\right)} & \text { otherwise }\end{cases}
$$

where $d$ is the ordinate of the highest intersection point two membership functions $\mu_{M_{1}}(x)$ and $\mu_{M_{2}}(x)$, as shown in Fig. 1.

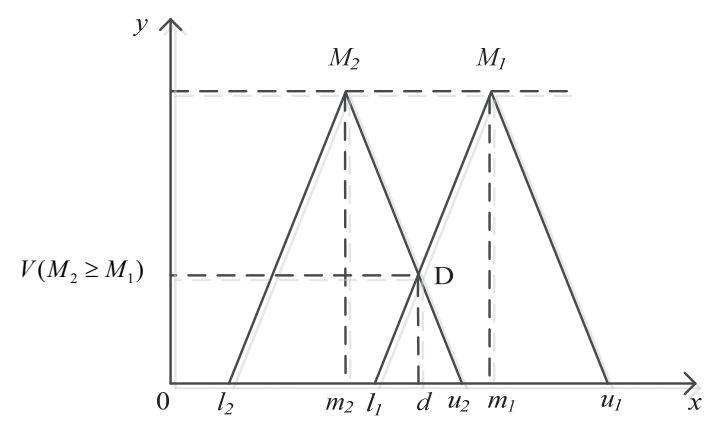

Fig.1. The comparison two fuzzy numbers

The degree of possibility for a convex fuzzy number to be greater than $k$ convex fuzzy numbers can be defined as:

$$
V\left(M \geq M_{1}, M_{2}, \ldots, M_{k}\right)=\min V\left(M \geq M_{i}\right), \quad i=1,2, \ldots, k .
$$

The weight vector of criteria $C_{m}$ is given by:

$$
\mathrm{W}^{\prime}=\left(d^{\prime}\left(C_{1}\right), d^{\prime}\left(C_{2}\right), \ldots, d^{\prime}\left(C_{f}\right)\right)^{T}
$$

where,

$$
C_{f}(f=1,2, \ldots, t), d^{\prime}\left(C_{f}\right)=\min V\left(S_{i} \geq S_{k}\right), k=1,2, \ldots, n ; k \neq i
$$


Via normalization, weight vectors can be obtained as:

$$
\mathrm{W}_{f}=\left(d\left(C_{1}\right), d\left(C_{2}\right), \ldots, d\left(C_{f}\right)\right)^{T}
$$

where, $\mathrm{W}_{f}$ is a non-fuzzy number. This study adopts a "Likert Scale" of fuzzy numbers to transform the linguistic values into TFNs, as shown in Table 1.

\section{Table 1}

Triangular fuzzy conversation scale

\begin{tabular}{clcc}
\hline Order & Linguistic values & Triangular fuzzy numbers & Reciprocal triangular fuzzy scale \\
\hline 1 & Unimportant (U) & $(1,1,1)$ & $(1,1,1)$ \\
3 & Slightly important (SL) & $(2,3,4)$ & $(1 / 4,1 / 3,1 / 2)$ \\
5 & Moderately important (MI) & $(4,5,6)$ & $(1 / 6,1 / 5,1 / 4)$ \\
7 & Seriously important (SI) & $(6,7,8)$ & $(1 / 8,1 / 7,1 / 6)$ \\
9 & Very seriously important (VSI) & $(8,9,9)$ & $(1 / 9,1 / 9,1 / 8)$ \\
\hline
\end{tabular}

\subsection{Calculating the weighted ratings of lecturers' research productivity versus criteria}

Using the Eqs. (3)-(6), the weighted ratings of lecturers' research productivity versus criteria can be calculated as:

$$
G_{e}=\frac{1}{t} \sum_{f=1}^{t} x_{e f} \times w_{f}, e=1, \ldots, s ; f=1, \ldots, t
$$

3.4. Derive $A_{e}^{+}, A_{e}^{-}, d_{e}^{+}$and $d_{e}^{-}$

The positive and negative ideal solutions are obtained respectively as follows:

$$
\begin{aligned}
& A_{e}^{+}=([1,1],[0,0],[0,0]) \\
& A_{e}^{-}=([0,0],[1,1],[1,1])
\end{aligned}
$$

The distances of each lecturer $A_{e}, e=1, \ldots, S$ from $A_{e}^{+}$and $A_{e}^{-}$are calculated as:

$$
\begin{aligned}
& d_{e}^{+}=d^{+}\left(G_{e}, A_{e}^{+}\right)=\sqrt{\frac{1}{6}\left(\begin{array}{l}
\left(T_{G_{e}}^{L}-T_{A_{e}^{+}}^{L}\right)^{2}+\left(T_{G_{e}}^{U}-T_{A_{e}^{+}}^{U}\right)^{2}+\left(I_{G_{e}}^{L}-I_{A_{e}}^{L}\right)^{2}+\left(I_{G_{e}}^{U}-I_{A_{e}}^{U} F_{A_{e}^{+}}^{L}\right)^{2}+\left(F_{G_{e}}^{U}-F_{A_{e}^{+}}^{U}\right)^{2} \\
+\left(F_{e}\right.
\end{array}\right.} \\
& d_{e}^{-}=d^{-}\left(G_{e}, A_{e}^{-}\right)=\sqrt{\frac{1}{6}\left(\begin{array}{l}
\left(T_{G_{e}}^{L}-T_{A_{\bar{e}}}^{L}\right)^{2}+\left(T_{G_{e}}^{U}-T_{A_{e}}^{U}\right)^{2}+\left(I_{G_{e}}^{L}-I_{A_{\bar{e}}}^{L}\right)^{2}+\left(I_{G_{e}}^{U}-I_{A_{\bar{e}}}^{U}\right)^{2} \\
+\left(F_{G_{e}}^{L}-F_{A_{e}}^{L}\right)^{2}+\left(F_{G_{e}}^{U}-F_{A_{e}}^{U}\right)^{2}
\end{array}\right.}
\end{aligned}
$$

where $d_{e}^{+}$is the shortest distance of alternative $A_{e}$, and $d_{e}^{-}$is the farthest distance of alternative $A_{e}$.

\subsection{Find the closeness coefficient and ranking order of alternatives}

The closeness coefficient of each alternative with respect to interval neutrosophic ideal solutions is calculated as:

$$
C C_{e}=\frac{d_{e}^{-}}{d_{e}^{+}+d_{e}^{-}}
$$

According to descending order of the closeness coefficient value, the raking order of each alternative can be identified. 


\section{Application of the proposed integrated MCDM approach for lecturers' research productivity evaluation}

In this section, the proposed integrated MCDM approach is applied to evaluate lecturers' research productivity in the case of UEB-VNU. Assume that the university needs to evaluate lecturers' research productivity at the end of year. Four lecturers are chosen for further evaluation. A committee of four decision makers were required to make their evaluation separately, according to their preferences for the importance weights of criteria and the ratings of alternative based on each criterion. After a discussion with committee members (department heads and lecturers at UEB-VNU), five criteria are selected including number of publications $\left(C_{1}\right)$, quality of publications $\left(C_{2}\right)$, number of books $\left(C_{3}\right)$, supervising postgraduate students $\left(C_{4}\right)$, research grants secured as project leader $\left(C_{5}\right)$. The computational procedure is summarized as follows:

\subsection{Aggregating the Ratings of Lecturers' research productivity versus the Criteria}

Assume that the committee members use the linguistic rating set $S=\{V L, L, M, H, V H\}$ where VL= Very Low $=([0.1,0.2],[0.6,0.7],[0.6,0.7]), \mathrm{L}=\operatorname{Low}=([0.2,0.3],[0.5,0.6],[0.6,0.7]), \mathrm{M}=$ Medium $=([0.3,0.5],[0.4,0.6],[0.4,0.5]), \mathrm{H}=$ High $=([0.5,0.6],[0.4,0.5],[0.3,0.4])$, and $\mathrm{VH}=$ Very High $=$ $([0.6,0.7],[0.2,0.3],[0.2,0.3])$ to evaluate the lecturers' research productivity under each criterion. Table 2 presents the aggregated ratings of the lecturers' research productivity from the committee members using Eq. (9).

\section{Table 2}

Aggregated ratings of lecturers' research productivity versus the criteria

\begin{tabular}{|c|c|c|c|c|c|c|}
\hline \multirow{2}{*}{ Criteria } & \multirow{2}{*}{ Lecturers } & \multicolumn{4}{|c|}{ Decision-makers } & \multirow{2}{*}{ Aggregated ratings } \\
\hline & & $D_{1}$ & $D_{2}$ & $D_{3}$ & $D_{4}$ & \\
\hline \multirow{4}{*}{$C_{1}$} & $A_{1}$ & $\mathrm{H}$ & $\mathrm{H}$ & $\mathrm{H}$ & VH & $([0.527,0.628],[0.336,0.440],[0.271,0.372])$ \\
\hline & $A_{2}$ & $\mathrm{H}$ & M & $\mathrm{H}$ & $\mathrm{H}$ & $([0.456,0.577],[0.400,0.523],[0.322,0.423])$ \\
\hline & $A_{3}$ & VH & $\mathrm{H}$ & VH & $\mathrm{H}$ & $([0.553,0.654],[0.283,0.387],[0.245,0.346])$ \\
\hline & $A_{4}$ & VH & $\mathrm{H}$ & $\mathrm{H}$ & VH & $([0.553,0.654],[0.283,0.387],[0.245,0.346])$ \\
\hline \multirow{4}{*}{$C_{2}$} & $A_{1}$ & $\mathrm{H}$ & $\mathrm{M}$ & $\mathrm{H}$ & $\mathrm{H}$ & $([0.456,0.577],[0.400,0.523],[0.322,0.423])$ \\
\hline & $A_{2}$ & M & $\mathrm{H}$ & M & $\mathrm{H}$ & $([0.408,0.553],[0.400,0.548],[0.346,0.447])$ \\
\hline & $A_{3}$ & $\mathrm{H}$ & $\mathrm{H}$ & $\mathrm{H}$ & M & $([0.456,0.577],[0.400,0.523],[0.322,0.423])$ \\
\hline & $A_{4}$ & VH & $\mathrm{H}$ & VH & $\mathrm{H}$ & $([0.553,0.654],[0.283,0.387],[0.245,0.346])$ \\
\hline \multirow{4}{*}{$C_{3}$} & $A_{1}$ & $\mathrm{~L}$ & $\mathrm{M}$ & $\mathrm{M}$ & $\mathrm{M}$ & $([0.276,0.456],[0.423,0.600],[0.443,0.544])$ \\
\hline & $A_{2}$ & $\mathrm{H}$ & $\mathrm{H}$ & M & $\mathrm{H}$ & $([0.456,0.577],[0.400,0.523],[0.322,0.423])$ \\
\hline & $A_{3}$ & $\mathrm{H}$ & $\mathrm{H}$ & VH & $\mathrm{H}$ & $([0.527,0.628],[0.336,0.440],[0.271,0.372])$ \\
\hline & $A_{4}$ & $\mathrm{H}$ & M & $\mathrm{H}$ & $\mathrm{M}$ & $([0.408,0.553],[0.400,0.548],[0.346,0.447])$ \\
\hline \multirow{4}{*}{$C_{4}$} & $A_{1}$ & $\mathrm{H}$ & VH & $\mathrm{H}$ & $\mathrm{H}$ & $([0.527,0.628],[0.336,0.440],[0.271,0.372])$ \\
\hline & $A_{2}$ & $\mathrm{H}$ & $\mathrm{M}$ & $\mathrm{H}$ & $\mathrm{H}$ & $([0.456,0.577],[0.400,0.523],[0.322,0.423])$ \\
\hline & $A_{3}$ & VH & $\mathrm{H}$ & $\mathrm{H}$ & VH & $([0.553,0.654],[0.283,0.387],[0.245,0.346])$ \\
\hline & $A_{4}$ & $\mathrm{H}$ & $\mathrm{H}$ & $\mathrm{H}$ & $\mathrm{H}$ & $([0.500,0.600],[0.400,0.500],[0.300,0.400])$ \\
\hline \multirow{4}{*}{$C_{5}$} & $A_{1}$ & $\mathrm{H}$ & VH & $\mathrm{H}$ & VH & $([0.553,0.654],[0.283,0.387],[0.245,0.346])$ \\
\hline & $A_{2}$ & $\mathrm{~L}$ & $\mathrm{M}$ & M & $\mathrm{M}$ & $([0.276,0.456],[0.423,0.600],[0.443,0.544])$ \\
\hline & $A_{3}$ & $\mathrm{H}$ & $\mathrm{H}$ & $\mathrm{H}$ & $\mathrm{H}$ & $([0.500,0.600],[0.400,0.500],[0.300,0.400])$ \\
\hline & $A_{4}$ & $\mathrm{H}$ & $\mathrm{VH}$ & $\mathrm{H}$ & $\mathrm{H}$ & $([0.527,0.628],[0.336,0.440],[0.271,0.372])$ \\
\hline
\end{tabular}

\subsection{Aggregating the importance weights of criteria}

This study applies Chang's (1996) method to define the importance weights of the lecturers' research productivity evaluation criteria. The committee members were required to make their evaluation separately, according to their preferences for the importance weights of criteria. By using the collected data from questionnaires and the triangular fuzzy conversation scale (in Table 1), an average fuzzy pair-wise comparison matrix of the criteria is defined in Table 3. 


\section{Table 3}

Average fuzzy comparison matrix of lecturers' research productivity evaluation criteria

\begin{tabular}{|c|c|c|c|c|c|c|c|c|c|c|c|c|c|c|c|}
\hline Criteria & \multicolumn{3}{|c|}{$C_{1}$} & \multicolumn{3}{|c|}{$C_{2}$} & \multicolumn{3}{|c|}{$C_{3}$} & \multicolumn{3}{|c|}{$C_{4}$} & \multicolumn{3}{|c|}{$C_{5}$} \\
\hline$C_{1}$ & 1.00 & 1.00 & 1.00 & 1.10 & 1.63 & 2.19 & 2.04 & 2.80 & 3.56 & 1.56 & 2.07 & 5 & 0.21 & 0.27 & \\
\hline$C_{2}$ & 2.13 & 2.67 & 3.25 & 1.00 & 1.00 & 1.00 & 1.10 & 1.63 & 2. & 3.50 & 4.5 & & 2.06 & 2.83 & 3.63 \\
\hline$C_{3}$ & 1.15 & 1.43 & 1.75 & 1.63 & 2.17 & 2.75 & 1.00 & 1.00 & 1.00 & 0.66 & 0.95 & 1.29 & 1.60 & 2.38 & 2.69 \\
\hline$C_{4}$ & 3.10 & 3.63 & 4.19 & 0.1 & 0.23 & 0.31 & 2.56 & 3.33 & 4.13 & 1.00 & 1.00 & 1.00 & 0.65 & 0.93 & 1.25 \\
\hline$C_{5}$ & 3.00 & 4.00 & 5.00 & 0.67 & 0.97 & 1.31 & 1.60 & 2.11 & 2.69 & 2.56 & 3.33 & 4.13 & 1.00 & 1.00 & 1.00 \\
\hline
\end{tabular}

Using Eq. (10) and Table 3, fuzzy synthetic extent values of criteria are calculated (See Table 4).

Table 4

Fuzzy synthetic extent values of lecturers' research productivity evaluation criteria

\begin{tabular}{cc}
\hline Criteria & Fuzzy synthetic extent \\
\hline$C_{1}$ & $(0.121,0.181,0.258)$ \\
$C_{2}$ & $(0.166,0.236,0.325)$ \\
$C_{3}$ & $(0.091,0.134,0.195)$ \\
$C_{4}$ & $(0.143,0.198,0.272)$ \\
$C_{5}$ & $(0.172,0.251,0.347)$ \\
\hline
\end{tabular}

Using Eqs. (11)-(16), the importance weights of lecturers' research productivity evaluation criteria are obtained (as shown in Table 5).

\section{Table 5}

The importance weights of the lecturers' research productivity evaluation criteria

\begin{tabular}{lccccc}
\hline Criteria & $C_{1}$ & $C_{2}$ & $C_{3}$ & $C_{4}$ & $C_{5}$ \\
\hline Weight score & 0.168 & 0.278 & 0.049 & 0.199 & 0.305 \\
\hline
\end{tabular}

\subsection{Compute the aggregate weighted rating of each lecturers' research productivity}

The aggregate weighted rating value of each lecturer can be obtained by multiplying the aggregated ratings of lecturers and the weight of criteria using Eq. (17) (as shown in Table 6). Table 7 presents the final average evaluation values of each lecturer.

\section{Table 6}

Aggregate weighted rating value of each lecturer

\begin{tabular}{ccc} 
Criteria & Lecturers & Aggregate weighted ratings \\
\multirow{4}{*}{$C_{1}$} & $A_{1}$ & $([0.118,0.153],[0.833,0.871],[0.803,0.847])$ \\
& $A_{2}$ & $([0.097,0.135],[0.857,0.897],[0.827,0.865])$ \\
& $A_{3}$ & $([0.127,0.163],[0.809,0.853],[0.789,0.837])$ \\
$C_{2}$ & $A_{4}$ & $([0.127,0.163],[0.809,0.853],[0.789,0.837])$ \\
& $A_{1}$ & $([0.156,0.213],[0.775,0.835],[0.730,0.787])$ \\
& $A_{2}$ & $([0.136,0.201],[0.775,0.846],[0.744,0.799])$ \\
& $A_{3}$ & $([0.156,0.213],[0.775,0.835],[0.730,0.787])$ \\
$C_{3}$ & $A_{4}$ & $([0.201,0.256],[0.704,0.768],[0.676,0.744])$ \\
& $A_{1}$ & $([0.016,0.029],[0.959,0.975],[0.961,0.971])$ \\
& $A_{2}$ & $([0.029,0.041],[0.956,0.969],[0.946,0.959])$ \\
$C_{4}$ & $A_{3}$ & $([0.036,0.047],[0.948,0.961],[0.938,0.953])$ \\
& $A_{4}$ & $([0.025,0.039],[0.956,0.971],[0.949,0.961])$ \\
& $A_{1}$ & $([0.139,0.179],[0.805,0.849],[0.771,0.821])$ \\
$C_{5}$ & $A_{2}$ & $([0.114,0.158],[0.833,0.879],[0.798,0.842])$ \\
& $A_{3}$ & $([0.148,0.190],[0.777,0.828],[0.755,0.810])$ \\
& $A_{4}$ & $([0.129,0.167],[0.833,0.871],[0.787,0.833])$ \\
& $A_{1}$ & $([0.218,0.276],[0.680,0.749],[0.651,0.724])$ \\
& $A_{2}$ & $([0.094,0.170],[0.769,0.856],[0.780,0.830])$ \\
& $A_{3}$ & $([0.191,0.244],[0.756,0.809],[0.692,0.756])$ \\
& $A_{4}$ & $([0.204,0.260],[0.717,0.778],[0.671,0.740])$ \\
\hline
\end{tabular}


Table 7

The final evaluation values of each lecturer

\section{Lecturers}

$A_{1}$
$A_{2}$
$A_{3}$
$A_{4}$

Aggregated weights

$([0.124,0.142\rceil,[0.839,0.881],[0.815,0.856\rceil)$

$([0.080,0.120],[0.861,0.906],[0.844,0.880])$

$([0.112,0.147],[0.839,0.878],[0.810,0.853])$

$([0.118,0.153],[0.829,0.869],[0.803,0.847])$

4.4. Derive $A_{e}^{+}, A_{e}^{-}, d_{e}^{+}$, and $d_{e}^{-}$

As shown in Table 8, the distance of each lecturer from $G_{e}$ can be calculated by Eqs. (18)-(21).

Table 8

Distance measurement

\begin{tabular}{ccc}
\hline Lecturers & $d_{e}^{+}$ & $d_{e}^{-}$ \\
\hline$A_{1}$ & 0.854 & 0.148 \\
$A_{2}$ & 0.882 & 0.121 \\
$A_{3}$ & 0.854 & 0.149 \\
$A_{4}$ & 0.847 & 0.156 \\
\hline
\end{tabular}

\subsection{Find the closeness coefficient and ranking order of each lecturer}

The closeness coefficients of the lecturers can be calculated by Eq. (22), as shown in Table 9. Results show that the lecturer $A 4$, with the largest closeness coefficient value, is defined as the best lecturer for the university. Therefore, the ranking order of the four lecturers is $A_{4} \succ A_{3} \succ A_{1} \succ A_{2}$.

Table 9

Closeness coefficients of lecturers

\begin{tabular}{ccc}
\hline Lecturers & Closeness coefficient & Ranking \\
\hline$A_{1}$ & 0.147 & 3 \\
$A_{2}$ & 0.121 & 4 \\
$A_{3}$ & 0.148 & 2 \\
$A_{4}$ & 0.156 & 1 \\
\hline
\end{tabular}

\section{Conclusion}

This study presented the integrated MCDM approach for the lecturers' research productivity evaluation. In the proposed integrated MCDM approach, the fuzzy AHP was applied to determine the importance weights of lecturers' research productivity evaluation criteria. The TOPSIS method was further adopted to evaluate and ranking the lecturers' research productivity. Finally, the have proposed integrated MCDM approach was applied to solve lecturers' research productivity evaluation in the case of UEB-VNU. Five criteria were used in the application including number of publications, quality of publications, number of books, supervising postgraduate students, and research grants secured as project leader. It has been demonstrated that the proposed integrated MCDM approach is efficient and easy to apply.

\section{Acknowledgment}

This research is funded by Vietnam National Foundation for Science and Technology Development (NAFOSTED) under grant number 503.01-2019.03.

\section{References}

Ateş, N. Y., Çevik, S., Kahraman, C., Gülbay, M., \& Erdoğan, S. A. (2006). Multi attribute performance evaluation using a hierarchical fuzzy TOPSIS method. In Fuzzy Applications in Industrial Engineering (pp. 537-572). Springer, Berlin, Heidelberg. 
Chang, D. Y. (1996). Applications of the extent analysis method on fuzzy AHP. European Journal of Operational Research, 95(3), 649-655.

Chang, T. C., \& Wang, H. (2016). A Multi Criteria Group Decision-making Model for Teacher Evaluation in Higher Education Based on Cloud Model and Decision Tree. Eurasia Journal of Mathematics, Science \& Technology Education, 12(5), 1243-1262.

e Costa, C. A. B., \& Oliveira, M. D. (2012). A multicriteria decision analysis model for faculty evaluation. Omega, 40(4), 424-436.

Cummings, W. K., \& Shin, J. C. (2014). Teaching and research in contemporary higher education: An overview. In J. C. Shin, A. Arimoto, W. K. Cummings, \& U. Teichler (Eds.), Teaching and research in contemporary higher education: Systems, activities and rewards (pp. 1-11). Dordrecht: Springer.

Dat, L. Q., Thong, N. T., Ali, M., Smarandache, F., Abdel-Basset, M., \& Long, H. V. (2019). Linguistic approaches to interval complex neutrosophic sets in decision making. IEEE access, 7, 38902-38917.

Do, A., Pham, M., Dinh, T., Ngo, T., Luu, Q., Pham, N., ... \& Vuong, H. (2020). Evaluation of lecturers' performance using a novel hierarchical multi-criteria model based on an interval complex Neutrosophic set. Decision Science Letters, 9(2), 119-144.

Dubois, D., \& Prade, H. (1978). Operations on fuzzy numbers. International Journal of systems science, 9(6), 613-626.

Hedjazi, Y., \& Behravan, J. (2011). Study of factors influencing research productivity of agriculture faculty members in Iran. Higher education, 62(5), 635-647.

Jaramillo, I. F., Pico, R. B., \& De La Plata, C. V. M. (2017). A Model for Faculty Evaluation in Higher Education Ecuadorian through Multi-Criteria Decision Analysis. Indian Journal of Science and Technology, 10, 18. DOI: 10.17485/ijst/2017/v10i18/110443

Karmaker, C. L., Ahmed, S. M. T., Rahman, M. S., Tahiduzzaman, M., Biswas, T. K., Rahman, M., \& Biswas, S. K. A framework of faculty performance evaluation: A case study in Bangladesh, 4(3), 18-24.

McKee, C. W., \& Tew, W. M. (2013). Setting the stage for teaching and learning in American higher education: Making the case for faculty development. New Directions for Teaching and Learning, 2013(133), 3-14.

Kaya, N., \& Weber, M. J. (2003). Cross-cultural differences in the perception of crowding and privacy regulation: American and Turkish students. Journal of Environmental Psychology, 23(3), 301-309

Smarandache, F. (1998). Neutrosophy: Neutrosophic Probability, Set, and Logic. Analytic Synthesis Synthetic Analysis. American Research Press.

Tauhed, S. Z., Rasdi, R. M., \& Ibrahim, R. (2019). The Influence of Networking, Individual Effort, and Time Management on Research Performance of Academics at Malaysian Research Universities. Revista Publicando, 6(19), 100-114.

Wang, H., Smarandache, F., Zhang, Y., \& Sunderraman, R. (2010). Single valued neutrosophic sets. Infinite study..

Wang, H., Smarandache, F., Sunderraman, R., \& Zhang, Y. Q. (2005). interval neutrosophic sets and logic: theory and applications in computing: Theory and applications in computing (Vol. 5). Infinite Study.

Wong, M. P. A., \& Tierney, W. G. (2001). Reforming Faculty Work: Culture, Structure, and the Dilemma of Organizational Change. Teachers College Record, 103(6), 1081-1101.



(C) 2020 by the authors; licensee Growing Science, Canada. This is an open access article distributed under the terms and conditions of the Creative Commons Attribution (CC-BY) license (http://creativecommons.org/licenses/by/4.0/). 